\title{
Health education models application by peer group for improving breast cancer screening among Iranian women with a family history of breast cancer: A randomized control trial
}

\author{
Fariba Fathollahi-Dehkordi ${ }^{1}$, Ziba Farajzadegan ${ }^{2 *}$ \\ Received: 2 Dec 2017 \\ Published: 21 June 2018
}

\section{Abstract}

Background: Studies have shown that participation of Iranian women with family history of breast cancer in screening service is low. This investigation has evaluated the effectiveness of health models according to peer group in improving clinical breast exam (CBE) among Iranian women with a family history of breast cancer.

Methods: This was a randomized control trial conducted during June and August 2015 in Isfahan. A total of 54 women were assigned into intervention and 53 to control group. Women 20 years or older with an affected relative were included. CBE screening, stage of change screening, knowledge, and belief were considered as outcomes after educational program. Data were analyzed by ANOVA and descriptive statistics by SPSS. Significance level was set at 0.025 .

Results: Investigation was completed by 98 women; and we considered $22 \%$ as effect size. Three months after the intervention, screening practice was $52 \%$ in interventional versus $18 \%$ in control group $(\mathrm{p}<0.001)$. Knowledge and all health belief subscales scores were significantly affected by time factor and time-group interaction $(\mathrm{p}<0.001)$. The effect of group factor was significantly related to knowledge score and perceived sensitivity, benefits, and health motivation subscales. Three months after the intervention, most women in the intermediation group were in the action stage of CBE compared to the controls who continued to be in contemplation stage $(\mathrm{p}<0.001)$.

Conclusion: Peer group interventions, which can be organized by health models, have positive effects on CBE in women with positive history of breast cancer.

Keywords: Breast cancer, Peer group, Health belief model, Transtheoretical model, Family history, Screening

Copyright $₫$ Iran University of Medical Sciences

Cite this article as: Fathollahi-Dehkordi F, Farajzadegan Z. Health education models application by peer group for improving breast cancer screening among Iranian women with a family history of breast cancer: A randomized control trial. Med J Islam Repub Iran.2018(21 June);32:51. https://doi.org/10.14196/mjiri.32.51

\section{Introduction}

During the last few decades, breast cancer screening methods have led to earlier diagnosis and improvement in the survival of breast cancer patients (1). Mammography is the best method for early detection of breast tumors; however, $\mathrm{CBE}$, which is done by an expert health worker, is a recommended complementary method to diagnose

Corresponding author: Dr Ziba Farajzadegan, farajzadegan@med.mui.ac.ir

1. Community Medicine Department, School of Medicine, Shahrekord University of Medical Sciences, Shahrekord, Iran.

2. Community Medicine Department, School of Medicine, Isfahan University of Medical Sciences, Isfahan, Iran. breast tumors and is less expensive than mammography, so it is a suitable method for low- to middle- income countries like Iran $(2,3)$. American Cancer Society (ACS) factsheet and figure in 2011-2012 recommended an annual CBE for women older than 40 years and a CBE every 3 years for women aged 20 to 40 years (3). However, ac-

$\uparrow$ What is "already known” in this topic:

Currently, there is no routine structural intervention to improve the beliefs and attitude of women with a family history of breast cancer about breast cancer screening programs in Iran. Women with a family history of breast cancer have higher risk for breast cancer.

$\rightarrow$ What this article adds:

Since educational intervention based on health education models by peer group is significantly associated with improving beliefs and screening behavior of women with a family history of breast cancer, this structural intervention can improve breast cancer screening, early detection, and treatment of this cancer. 
cording to a review article by Naghibi et al. only $25 \%$ of Iranian women undergo routine CBE (4). Furthermore, Iranian breast cancer patients are about 10 years younger than their Western counterparts, which makes breast cancer one of the major health concerns for Iranian women (5). Women with a family history of breast cancer, especially in their first relatives, have a higher risk for breast cancer compared to others (3). However, studies have shown that the rate of participation in breast cancer screening programs is low in this at risk group (6). Several studies have shown that women's knowledge, perceived level of sensitivity, risk perception, health motivation, and potential benefit and harm from screening method influence their willingness to participate in breast cancer screening programs (7-9).

Considering behavioral motivators and barriers of breast cancer screening, using health models can help improve cancer screening participation, as these models help focus on factors associated with behavior change. The health belief model (HBM) is one of the most wildly used health models. This model postulates people will take action if they perceive the sensitivity and severity of that situation and it benefits from taking that action to out weight the barriers and side effects (10). This model has been used in several studies to improve breast cancer screening behaviors among women through group education, film education, text education, and peer education. Peer group based interventions are appropriate for implementing HBM by improving perception and attitude toward health related behaviors, such as cancer screening participation. In this method, peers communicate better with each other and express their strengths and weaknesses and encourage health behaviors (12-15). Malekpour study showed the effect of peer group on improving life quality in patients with breast cancer (11). Gözüm et al. reported that peer group education is an effective method to improve breast cancer screening participation (12).

One of the major concerns in using peer group based interventions to educate people and promote health related behaviors is selecting appropriate educators and participants. One method of selecting the educator for peer groups is according to the transtheoretical model (TTM).

TTM assumes that people are in different stages of adapting a specific behavior. According to this model, behavior can be categorized as a process occurring through a series of stages: precontemplation, contemplation, preparation, action, and maintenance; also, people can relapse from action to contemplation stage (13). Moodi reported that Iranian women in action and maintenance stage of breast cancer screening have higher perceived benefits and motivation toward that behavior (14). In this study, we considered women in action or maintenance stages of CBE as peer educators and women in precontemplation, contemplation, and relapse stages as participants.

Few studies have evaluated interventions that promote participation of Iranian women with a family history of breast cancer in cancer screening programs. In this study, we evaluated the effectiveness of health models based intervention by peer group in promoting breast cancer screening behavior and belief in women with a family history of breast cancer.

\section{Methods}

This was a randomized controlled trial designed to evaluate the effectiveness of a 3-week peer group intervention in improving knowledge and health beliefs about CBE.

\section{Ethical consideration}

The Medical Ethics Committee of Isfahan University of Medical Sciences approved the study design (registration code: IRCT2015051921447N2).

\section{Participants and setting}

Our target population was women with a family history of breast cancer in their first or second degree relatives who referred to S. Al- Shohada hospital, the main cancer treatment center in Isfahan during June and August 2015 in Isfahan, Iran. We aimed at evaluating the use of breast cancer screening method as the primary outcome, and women's beliefs about breast cancer and its screening and changes in their screening behavior according to TTM as the second outcomes. The use of breast cancer screening method was applied for sample size determination. So, we estimated our initial sample size to be 94 participants (47 participants/group) by considering $80 \%$ for study power $\left(\mathrm{z}_{\beta}=0.84\right)$, with a 0.05 one-sided significant level, $\mathrm{p}_{1}=16 \%, \mathrm{p}_{2}=38 \%$, effect size $=22 \%$. However, considering $10 \%$ drop out, every group consisted of 52 participants (15).

Inclusion criteria for women under investigation were as follow: women 20 years or older; being in precontemplation, contemplation, or relapse stage of breast cancer screening according to TTM; living in Isfahan; and being a first or second degree relative of a breast cancer patient, who referred to Sayed-Al Shohada hospital. Those women who were not willing to participate in the program and who participated in less than 2 interventional sessions were excluded. Moreover, pregnant or lactating women or those women with breast cancer were also excluded.

After obtaining informed consent from each patient, basic information for every eligible woman was collected by a trained interviewer in a noiseless room in the hospital at the initial meeting.

At first, participants were selected by easy sampling method, and were, then, randomized into intervention and control groups by computerized random numbers.

The interviewer, who gathered information from participants, was blind to group allocation. Also, groups were coded (Codes 1 and 2), and the analyzer was also blind o group allocation.

A total of 5 women were selected as peer educators (4 were principle and 1 was substitute). Inclusion criteria for selecting peer educators were as follow: women 20 years or older, volunteering to participate in the program, living in Isfahan, and being the first or second degree relative of a breast cancer patient who accompanied the patient when referring to Sayed-Al.Shohada hospital, having at least high school deploma, and being in the action or maintenance stages of breast cancer screening according to TTM. 


\section{Instruments}

Each questionnaire contained 4 sections: sociodemographic information, knowledge about breast cancer, beliefs about breast cancer, and CBE behavior and CBE behavior stage of change according to TTM.

\section{Sociodemographic}

We collected participants' data about age, education status, employment status, marital status, history of breast disease, income status, and insurance.

\section{Breast cancer knowledge}

A 12- item false-true checklist was used to evaluate participants' knowledge about breast cancer (1 item), risk factors (5 items), signs and symptoms (3 items), and screening methods (3 items). Each correct answer was given a score of 1 . Final score for each participant was calculated. The minimum score was 0 and the maximum was 12 .

\section{Breast cancer health beliefs}

To evaluate participants' beliefs about breast cancer and CBE behavior, we used the Persian version of the last Champion Revised Health Belief Model Scale (CHBMS). This construct was standardized by Taymoori and berry for Iranians. This tool consists of 8 sections with a lickert scale. Each question has a range of response from strongly disagree (1) to strongly agree (5). In this study, we used 5 subscales of this construct including perceived sensitivity (3 items, Cronbach a=0/82 ), severity ( 7 items, Cronbach $\mathrm{a}=0 / 84)$, barriers (10 items, Cronbach $\mathrm{a}=0 / 73)$, benefits (6 items, Cronbach $\mathrm{a}=0 / 72$ ), and health motivation (7 items, Cronbach $a=0 / 77)(16)$.

\section{CBE stage of change}

Women's TTM stages as applied to CBE were assessed according to Rakoweski classification stages:

a) Precontemplation: No prior $\mathrm{CBE}$ and not thinking about receiving one in the next 12 ( $\geq 40$ years old) or 36 ( $<40$ years old) months

b) Contemplation: No prior $\mathrm{CBE}$, but thinking about receiving one in the next $12(\geq 40$ years old) or $36(<40$ years old) months

c) Relapse: One or more prior CBE, but no expectation of receiving another in the next 12 ( $\geq 40$ years old) or 36 ( $<40$ years old) months

d) Action: A prior $\mathrm{CBE}$ and an expectation of receiving another in the next $12(\geq 40$ years old) or $36(<40$ years old) months

e) Maintenance: Two or more prior CBE and an expectation of receiving another in the next $12(\geq 40$ years old) or 36 (<40 years old) months (17)

\section{Intervention}

The intervention program was offered in 3 weekly sessions by a peer educator. All sessions were held by oral presentation, group discussion, and image presentation.

At first, an educational program was held for peer educators by a researcher in 3 sessions based on HBM. Dur- ing these sessions, different issues about breast cancer were discussed, such as breast cancer risk factors, signs and symptoms, screening methods, benefits of early diagnosis, ways to increase perceived sensitivity, and severity about breast cancer screening, methods to improve motivation, and methods to overcome screening barriers. The purpose of these sessions was to organize educators' information about breast cancer and screening methods, enable them to conduct sessions, and prevent them to discuss irrelevant subjects that may be propound during the sessions. Education content was offered to peer educators; also, a phone number was provided for probable questions. After preparation of the peer group educator, she devided the participants into 4 groups with 10 to 15 women in each. The peer educator provided 3 sessions for each group in 3 weeks, with each session lasting at least 2 hours. In each session, participants shared their knowledge and beliefs about breast cancer and screening methods. Also, the educator expressed her beliefs and experiences to improve participants' perceived sensitivity and severity about breast cancer screening and benefits achieved by regular screening. Also, she provided suggestions to decrease barriers towards screening. In the entire sessions, the researcher tried to ensure the scientific accuracy of the information. The participants were encouraged to stay connected with each other after the sessions to share their new experiences and help each other to overcome screening barriers.

One and 3 months after the intervention, the initial questionnaire was filled out for each participant in both intervention and control groups through a phone call. The interviewer was blind about the group allocation of the participants.

For ethical reasons, the control group were invited to participate in an educational session at the end of the follow- up. In this session, peer educators and the researcher were present and education content was offered to the control group; also, a phone number for phone consultations or questions were provided to them.

\section{Statistical analyses}

Data were analyzed using SPSS 16. To present our findings, we used mean, standard deviation, absolute frequency, and percent for quantitative and qualitative variables, respectively. To find the differences within and between groups, before, 1 month, and 3 months after the intervention, repeated measure ANOVA was applied. Chi square test and Fisher's exact test were used to compare the frequency distribution of the nominal and ordinal variables. Statistical significance was set at 0.025 .

\section{Results}

From 200 eligible participants, 38 (19\%) did not want to participate in the study (response rate $81 \%$ ). Moreover, 55 women were in action or maintenance stages of breast cancer screening behavior, according to TTM. Thus, 107 women were enrolled in the study after obtaining written informed consent (54 women in the intervention and 53 in the control group). At the beginning of the intervention, 9 


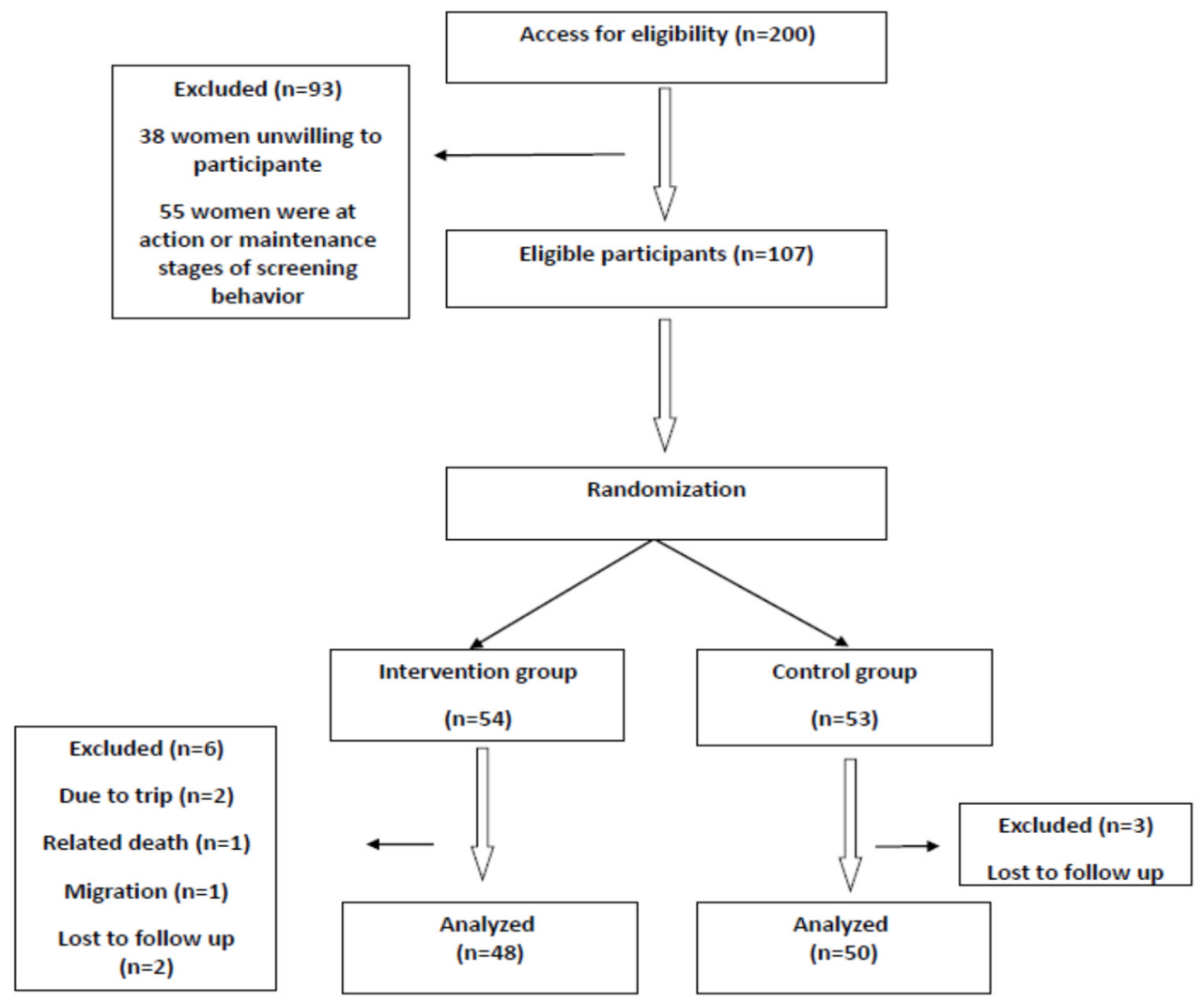

Fig. 1. Flow diagram of women assigned to control and intervention groups

women were excluded. Four women participated in less than 2 sessions because of trip $(n=2)$, relative's death $(n=1)$, and migration $(n=1)$. Moreover, 5 women were lost to follow- up ( 2 in the intervention group and 3 in the control group). Finally, 98 women completed the study (Fig. 1).
The baseline characteristics and demographic variables of the participants are summarized in Table 1A.

Mean age of the participants in the intervention and control groups was $36.04 \pm 10.90$ and $35.58 \pm 10.22$, respectively $(\mathrm{p}=0.820)$. There was no significant difference between the 2 groups in baseline characteristics and their

Table 1A. Baseline characteristics of the participants

\begin{tabular}{|c|c|c|c|}
\hline Variable & $\begin{array}{c}\text { Intervention group } \\
\mathrm{N}(\%)\end{array}$ & $\begin{array}{c}\text { Control group } \\
\mathrm{N}(\%)\end{array}$ & $\bar{p}$ \\
\hline \multicolumn{4}{|l|}{ Marital status } \\
\hline Married & $38(79.2)$ & $37(74)$ & $0.362 *$ \\
\hline Single or widow & $10(20.8)$ & $13(26)$ & \\
\hline \multicolumn{4}{|l|}{ Education } \\
\hline High school or less & $16(33.3)$ & $13(26)$ & $0.733 *$ \\
\hline Diploma & $15(31.3)$ & $17(34)$ & \\
\hline College education & $17(35.4)$ & $20(40)$ & \\
\hline \multicolumn{4}{|l|}{ Employment } \\
\hline Employment & $4(8.3)$ & $8(16)$ & $0.250 *$ \\
\hline Unemployment & $44(91.7)$ & $42(84)$ & \\
\hline \multicolumn{4}{|l|}{ Health insurance } \\
\hline Yes & $46(95.8)$ & $44(88)$ & $0.192 * *$ \\
\hline No & $2(4.2)$ & $6(12)$ & \\
\hline \multicolumn{4}{|l|}{ Income status } \\
\hline$<300 \$$ & $24(50)$ & $29(58)$ & $0.460 *$ \\
\hline $300-600 \$$ & $20(41.7)$ & $15(30)$ & \\
\hline $600 \$<$ & $4(8.3)$ & $6(12)$ & \\
\hline \multicolumn{4}{|l|}{ Breast disease history } \\
\hline Yes & $11(22.9)$ & $8(16)$ & $0.391 *$ \\
\hline \multirow{2}{*}{\multicolumn{4}{|c|}{ Relative degree }} \\
\hline & & & \\
\hline First & 35 (72.9) & $32(64)$ & $0.345^{*}$ \\
\hline second & $13(27.1)$ & $18(36)$ & \\
\hline
\end{tabular}

**Fisher's Exact Test 
Table 1B. Baseline characteristics of the participants

\begin{tabular}{lccc}
\hline Variable & $\begin{array}{c}\text { Intervention group } \\
\text { Mean } \pm \text { SD }\end{array}$ & $\begin{array}{c}\text { Control group } \\
\text { Mean } \pm \text { SD }\end{array}$ & $\mathrm{p}^{*}$ \\
\hline Knowledge & $6.89 \pm 1.88$ & $7.44 \pm 1.89$ & 0.164 \\
Perceived sensitivity & $9.50 \pm 2.20$ & $8.8 \pm 2.49$ & 0.152 \\
Perceived severity & $21.02 \pm 4.17$ & $22.70 \pm 4.78$ & 0.070 \\
CBE perceived benefits & $18.67 \pm 2.44$ & $18.26 \pm 2.78$ & 0.456 \\
CBE perceived barriers & $20.37 \pm 5.59$ & $19.5 \pm 5.17$ & 0.422 \\
Health motivation & $22.83 \pm 4.59$ & $22.98 \pm 4.31$ & 0.871 \\
\hline
\end{tabular}

Table 2. Analysis of variance for the evaluation of the main and interactive effects of time and group on knowledge and health beliefs subscales in participants

\begin{tabular}{|c|c|c|c|c|c|c|c|c|c|}
\hline Variable & $\mathrm{df}$ & $\begin{array}{c}\text { Time } \\
\mathrm{F}\end{array}$ & $\mathrm{p}$ & $\mathrm{df}$ & $\begin{array}{c}\text { Group } \\
\text { F }\end{array}$ & $\bar{p}$ & $\mathrm{df}$ & $\begin{array}{c}\text { Time*Group } \\
\text { F }\end{array}$ & $\mathrm{p}$ \\
\hline Knowledge & 2 & 150.86 & $<0.001$ & 1 & 22.27 & $<0.001$ & 2 & 121.34 & $<0.001$ \\
\hline Perceived Sensitivity & 2 & 18.05 & $<0.001$ & 1 & 7.99 & 0.006 & 2 & 12.43 & $<0.001$ \\
\hline Perceived Severity & 2 & 11.65 & $<0.001$ & 1 & 0.36 & 0.552 & 2 & 10.34 & $<0.001$ \\
\hline CBE perceived benefits & 2 & 46.94 & $<0.001$ & 1 & 11.98 & 0.001 & 2 & 29.78 & $<0.001$ \\
\hline CBE perceived barriers & 2 & 46.39 & $<0.001$ & 1 & 2.98 & 0.087 & 2 & 46.54 & $<0.001$ \\
\hline Health motivation & 2 & 84.37 & $<0.001$ & 1 & 7.09 & 0.009 & 2 & 73.74 & $<0.001$ \\
\hline
\end{tabular}

demographic variables. Most of the women in the 2 groups were married, had college education, were unemployment, had health insurance, had monthly income of less than $\$ 300$, and did not have a history of breast disease.

The mean score of knowledge and HBM of the 2 groups at baseline are illustrated in Table 1B; according to this table, there was no significant difference between the 2 groups.

Repeated measures ANOVA showed that knowledge score and all the health beliefs subscales scores were significantly affected through time factor and time-group interaction $(p<0.001)$. On the other hand, the effect of group factor was significantly related to knowledge score and perceived sensitivity, benefits and health motivation subscales (Table 2).

Bonferroni post hoc test showed a significant mean difference in the knowledge score and sensitivity, benefit, and health motivation subscale score between the control and intervention groups (Table 3).

Results of statistical analyses related to variations in the knowledge score and health beliefs subscales in the 2 groups and at different times (baseline, after 1 month, and after 3 months) are demonstrated in Table 4.

The score of knowledge and all the health beliefs subscales, excluding barriers in the intervention group, signif-

Table 3. Comparison of the mean differences of knowledge and health beliefs subscales between the 2 groups

\begin{tabular}{lcc}
\hline & $\mathrm{pD}(\mathrm{mean} \pm \mathrm{SD})$ & $0.001<$ \\
\hline Knowledge & $1.62 \pm 0.34$ & 0.006 \\
Perceived Sensitivity & $1.27 \pm 0.45$ & 0.552 \\
Perceived Severity & $0.54 \pm 0.91$ & 0.001 \\
CBE perceived benefits & $1.71 \pm 0.49$ & 0.087 \\
CBE perceived barriers & $1.79 \pm 1.04-$ & 0.009 \\
Health motivation & $2.34 \pm 0.88$ & \\
\hline
\end{tabular}

Table 4. Comparison of the mean differences of knowledge and health beliefs subscales between the 2 groups before, 1 month and 3 months after the intervention

\begin{tabular}{|c|c|c|c|c|c|c|c|}
\hline Variable & Groups & $\begin{array}{l}\text { Baseline- after } 1 \\
\text { months } \\
\operatorname{MD}(\text { mean } \pm \mathrm{Sd})\end{array}$ & $\mathrm{p}^{*}$ & $\begin{array}{c}\text { Baseline-after } 3 \\
\text { months } \\
\mathrm{MD}(\text { mean } \pm \mathrm{Sd})\end{array}$ & $\mathrm{p}$ & $\begin{array}{c}\text { After } 1 \\
\text { months }- \text { After } 3 \text { months } \\
M D(\text { mean } \pm \text { Sd })\end{array}$ & $\mathrm{p}^{*}$ \\
\hline \multicolumn{8}{|l|}{ Knowledge } \\
\hline & Intervention & $-3.50 \pm 0.25$ & $<0.001$ & $-3.37 \pm 0.23$ & $<0.001$ & $0.13 \pm 0.16$ & 1.000 \\
\hline & Control & $-0.14 \pm 0.09$ & 0.491 & $-0.24 \pm 0.11$ & 0.115 & $0.10 \pm 0.11$ & 1.000 \\
\hline \multirow[t]{2}{*}{$\begin{array}{l}\text { Perceived sensi- } \\
\text { tivity }\end{array}$} & Intervention & $-1.25 \pm 0.23$ & $<0.001$ & $-0.81 \pm 0.21$ & 0.002 & $0.44 \pm 0.17$ & 0.033 \\
\hline & Control & $-0.08 \pm 0.12$ & 1.000 & $-0.26 \pm 0.12$ & 0.108 & $-0.18 \pm 0.12$ & 0.422 \\
\hline \multicolumn{8}{|l|}{ Perceived severity } \\
\hline & Intervention & $-2.15 \pm 0.41$ & $<0.001$ & $-1.25 \pm 0.45$ & 0.031 & $0.94 \pm 0.41$ & 0.081 \\
\hline & Control & $-0.08 \pm 0.17$ & 1.000 & $0.14 \pm 0.22$ & 1.000 & $0.22 \pm 0.19$ & 0.790 \\
\hline \multicolumn{8}{|l|}{ CBE perceived } \\
\hline & Control & $-0.26 \pm 0.14$ & 0.221 & $-0.24 \pm 0.14$ & 0.289 & $0.02 \pm 0.13$ & 1.000 \\
\hline $\begin{array}{l}\text { CBE perceived } \\
\text { barriers }\end{array}$ & Intervention & $4.04 \pm 0.49$ & $<0.001$ & $3.96 \pm 0.53$ & $<0.001$ & $-0.08 \pm 0.28$ & 1.00 \\
\hline & Control & $-0.10 \pm .19$ & 1.000 & $0.10 \pm 0.21$ & 1.00 & $0.20 \pm 0.16$ & 0.644 \\
\hline \multicolumn{8}{|l|}{ Health motivation } \\
\hline & Intervention & $-4.58 \pm 0.42$ & $<0.001$ & $-3.21 \pm 0.31$ & $<0.001$ & $1.38 \pm 0.33$ & $<0.001$ \\
\hline & Control & $-0.12 \pm 0.15$ & 1.000 & $-0.22 \pm 0.18$ & 0.504 & $-0.1 \pm 0.09$ & 0.906 \\
\hline
\end{tabular}




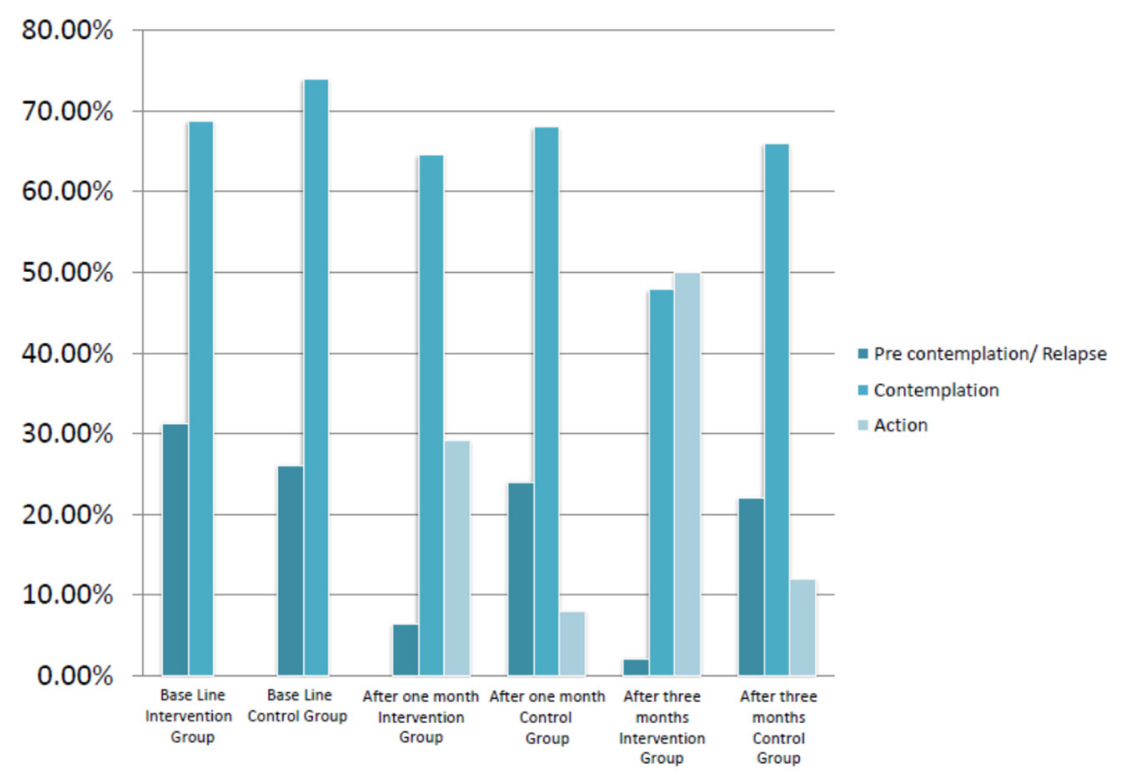

Fig. 2. Clinical breast exam stages of change before and after the intervention

Table 5. Comparison of CBE screening method between the 2 groups

\begin{tabular}{lccc}
\hline Variable & $\begin{array}{c}\text { Baseline } \\
\mathrm{N}(\%)\end{array}$ & $\begin{array}{c}\text { After 1 month } \\
\mathrm{N}(\%)\end{array}$ & $\begin{array}{c}\text { After 3 months } \\
\mathrm{N}(\%)\end{array}$ \\
\hline Intervention & & & \\
CBE & $7(14.6)$ & $16(33.3)$ & $25(52.1)$ \\
No CBE & $41(85.4)$ & $32(66.7)$ & $23(47.9)$ \\
& & & \\
Control & $5(10)$ & $7(14)$ & $9(18)$ \\
CBE & $45(90)$ & $43(86)$ & $41(82)$ \\
No CBE & 0.350 & 0.024 & $<0.001$ \\
P value (Chi-Square) & &
\end{tabular}

icantly increased when comparing baseline and 1 month after the intervention. With respect to baseline and 3 months after the intervention, we obtained similar results to baseline and 1 month after the intervention, excluding perceived severity. With respect to perceived barriers, these scores were significantly decreased in said times. Health motivation score was significantly different 1 and 3 months after the intervention.

There was no difference in the score of knowledge and health beliefs subscales in the control group when comparing different times (Table 4).

Distribution of CBE stages of change according to TTM is shown in Fig. 2. Chi square test revealed a significant difference in distribution of CBE stages of change at 3 months after the intervention $(\mathrm{p}=0.004, \mathrm{p}<0.001$, respectively) according to TTM 1. Before the intervention, most of the women in both groups were in contemplation stage of CBE, 33(68.8\%) in the intervention and $37(74 \%)$ in the control group $(p=0.565)$. Three months after the intervention, most women in the intervention group were in action stage of CBE (24 (50\%)), however, women in the control group continued to be mainly in contemplation stage of CBE (33 (66\%)).

Breast cancer screening practice of participants is displayed in Table 5. There was no significant difference between the 2 groups in CBE screening practice at baseline. However, chi square test revealed that $25(52 \%)$ of women in the intervention group had a CBE screening practice 3 months after the intervention compared to 9 $(18 \%)$ in the control group $(\mathrm{p}<0.001)$.

\section{Discussion}

This study was conducted to evaluate the effectiveness of health models based intervention by peer group on breast cancer screening in women with a family history of breast cancer. These findings support the model based intervention by peer group for improving knowledge and beliefs of women with a family history of breast cancer.

Our study results showed a significant increase in $\mathrm{CBE}$ practice in intervention group after the program, and these findings were similar to those of previous studies on the effectiveness of intervention on breast cancer screening behaviors based on peer group education and HBM (12), high risk group education and HBM (18), and group education and HBM (17). There was a significant difference between the 2 groups in CBE practice 1 and 3 months after the study. Hajian and Ahmad findings showed similar findings in the interventions based on high risk group education and HBM and a tailored intervention with transtheoretical concept, respectively $(18,19)$.

Our finding showed women's knowledge and all HBM constructs applicable to CBE screening method were significantly affected through time and time-interaction factors. Our findings were similar to those of Rezaeian and 
Hajian. Their studies showed that an educational intervention based on HBM has a significantly positive effect on sensitivity, severity, participants' knowledge, CBE benefit, and barriers towards breast cancer and its screening in women $(18,20)$. Although there was an increase in intervention group's knowledge and beliefs about breast cancer and its screening between baseline and 1 month after the intervention and between baseline and 3 months after the intervention, we observed a decrease in health motivation between 1 and 3 months after the intervention. Nevertheless, even after 3 months, level of participants' health motivation was significantly higher than baseline. This decline in the level of health motivation towards breast cancer screening may be due to negligence, distraction, or becoming occupied with other issues over time. On the other hand, health motivation score was related to person's behavior. This subject emphasizes the importance of periodic or continuous interventional programs for maintaining health behavior. The score of perceived severity did not significantly differ between baseline and 3 months after the intervention; however, it was near significance level. This result may be related to study sample size. Our results showed the effect of group factor on knowledge, perceived sensitivity, benefits, and health motivation. This finding supports the role of structural intervention in increasing health motivation and knowledge, perceived sensitivity, and benefits towards screening. This finding confirmed the results of previous studies $(12,18)$.

Our finding did not show the effect of factor group on perceived severity and barriers. This finding was in contrast to findings published by Rezaeian, who fiund a significant difference in participants' perceived severity after HBM based intervention in Iranian women (20). This may be due to the difference between the 2 studies' target groups. In our study, women had a family history of breast cancer, which could considerably increase perceived severity and decrease barriers about breast cancer at baseline. This can neutralize the effect of education on perceived severity and barriers.

Our study revealed that before the study, the majority of women in both groups were in contemplation stage of TTM. However, most of the intervention participants were in action stage of TTM 3 months after the study, but the majority of control participants were still in the contemplation stage of CBE, according to TTM. This may be due to increasing beliefs related to $\mathrm{CBE}$ screening behavior, which were confirmed in this study. These beliefs can be mediator factors in the behavioral change process of early diagnosis programs. Moodi et al. found the same results among Iranian women (17). Furthermore, Champion et al. supported our results (10).

\section{Conclusion}

It seems that a structured intervention based on peer group can successfully improve participants' knowledge, beliefs, and CBE behavior applied as TTM in at risk women, such as those with a family history of breast cancer. Thus, it can be used as a primary preventive program among Iranian women.

\section{Limitations}

In this study, we did not evaluate peer group's impact on other predictors of screening behavior, such as psychosocial factors. Furthermore, follow- up period was only 3 months, which might have overestimated the effect of the intervention.

We suggest that future studies evaluate other screening predictors that can be influenced by peer group education. A longer follow- up period is also advisable for future studies.

\section{Acknowledgements}

We acknowledge the supportive service at Saied- AlShohada hospital for providing assistance with this project. This project was supported by Isfahan University of Medical Sciences as a dissertation project $(\mathrm{no}=394130)$.

\section{Conflict of Interests}

The authors declare that they have no competing interests.

\section{References}

1. Ahmad F, Stewart DE. Predictors of clinical breast examination among South Asian immigrant women. J Immigr Health. 2004;6(3):119-26.

2. Parsa P, Kandiah M. Predictors of adherence to clinical breast examination and mammography screening among Malaysian women. Asian Pac J Cancer Prev. 2010;11(3):681-8.

3. American Cancer Society,(ACS). Cancer facts \& Figures 2011-2012. Atlanta: ACS; 2012;13.

4. Naghibi SA, Shojaizadeh D, Yazdani CJ, Montazeri A.Breast cancer preventive behaviors among Iranian women. Payesh. 2015;2:18191.

5. Thomas E, Escandón S, Lamyian M, Ahmadi F, Setoode SM, Golkho S. Exploring Iranian women's perceptions regarding control and prevention of breast cancer. Qual Rep. 2011;16(5):12-14.

6. Naghibi SA, Shojaizadeh D, Montazeri A, Yazdani-Cherati J. Evaluating the performance rate of breast cancer screening methods and its relationship with breast cancer risk factors in Mazandaran province, Iran. J Mazandaran Univ Med Sci. 2014;23(110):118-23.

7. Lemon SC, Zapka JG, Clemow L. Health behavior change among women with recent familial diagnosis of breast cancer. Prev Med. 2004;39(2):253-62.

8. Charkazi A, Samimi A, Razzaghi K, Kouchaki GM, Moodi M, Meirkarimi K, et al. Adherence to recommended breast cancer screening in Iranian Turkmen women: the role of knowledge and beliefs. Prev Med. 2013;563-72.

9. Farajzadegan Z, Fathollahi-Dehkordi F, Hematti S, Sirous R, Tavakoli N, Rouzbahani R. The transtheoretical model, health belief model, and breast cancer screening among Iranian women with a family history of breast cancer. J Res Med Sci. 2016;21:122.

10. Champion V, Maraj M, Hui S, Perkins AJ, Tierney W, Menon U, et al. Comparison of tailored interventions to increase mammography screening in nonadherent older women. Prev Med. 2003;36(2):1508.

11. Tehrani AM, Farajzadegan Z, Mokarian F, Zamani AR. Belonging to a peer support group enhance the quality of life and adherence rate in patients affected by breast cancer: a non-randomized controlled clinical trial. J Res Med Sci. 2011;16(5):658-65.

12. Gözüm SP, Karayurt Ö, Kav S, Platin N. Effectiveness of Peer Education for Breast Cancer Screening and Health Beliefs in Eastern Turkey. Cancer Nurs. 2010;33(3):213-20.

13. Choi JH, Chung KM, Park K. Psychosocial predictors of four health-promoting behaviors for cancer prevention using the stage of change of Transtheoretical Model. Psychooncology. 2013;22:2253-61.

14. Moodi M, Hassanzadeh A, Charkazi A, Shahnazi H, Sharifirad G. Survey of the Psycho-Cognitive Factors Affecting Breast Cancer Screening Behaviors at Different Stages of Change among Female 
Teachers in Isfahan, Iran. Journal of the Health System Research. 2011;7(6):770-81.

15. Janz NK, Schottenfeld D, Doerr KM, Selig SM, Dunn RL, Strawderman M, et al. A two-step intervention of increase mammography among women aged 65 and older. Am J Public Health. 1997;87(10):1683-6.

16. Taymoori P, Berry T. The validity and reliability of Champion's Health Belief Model Scale for breast cancer screening behaviors among Iranian women. Cancer Nurs. 2009;32(6):465-72.

17. Moodi M, Sharifirad GR, Rezaeian M, Mostafavi F, Tahergorabi Z, Shaykhfatholahi M. Promoting mammography screenig using telephone follow-up. Global Journal on Technology. 2015;9:79-86.

18. Hajian S, Vakilian K, Najabadi KM, Hosseini J, Mirzaei HR. Effects of education based on the health belief model on screening behavior in high risk women for breast cancer, Tehran, Iran. Asian Pac J Cancer Prev. 2011;12(1):49-54.

19. Ahmad F, Cameron JI, Stewart DE. A tailored intervention to promote breast cancer screening among South Asian immigrant women. Soc Sci Med. 2005;60(3):575-86.

20. Rezaeian M, Sharifirad G, Mostafavi F, Moodi M, Abbasi MH. The effects of breast cancer educational intervention on knowledge and health beliefs of women 40 years and older, Isfahan, Iran. J Educ Health Promot. 2014;3:43. 